\title{
Fluid and Stable Structures in the Organisational Communication of the Modern Society
}

\author{
KOME - An International Journal of Pure \\ Communication Inquiry \\ Volume 2 Issue 1 p. 23-32. \\ (C) The Author(s) 2013 \\ Reprints and Permission: \\ kome@komejournal.com \\ Published by the Hungarian Communication
} Studies Assoiciation

\author{
Bulcsu Bognár \\ Pázmány Péter Catholic University, Institute of Communication and Media Studies, Hungary
}

\begin{abstract}
This study focuses on one of the basic questions of Luhmann's social theory relating to the description of modernity, namely, on the characteristics of organisations, even more specifically, it is aimed at gaining new recognitions concerning the relationships between the functional subsystems and the organisations. Organisations, one of the most important levels of today's society, is analysed in the context of Luhmann's general social theory. The approach taken in the study originates from Luhmann's analysis of subsystems during the late period of his work. The author argues that vertical relationships between subsystems make up a typical feature of modern society as well. In its analysis of the organisations of modern society this study works out an interpretation of the relationship between stable and fluid structures in the process of communication, highlighting the frequently or continuously changing 'rationality preference' of organisations and it argues for the necessity a more complex analysis of organisational communication. At the same time the study points out by analysing the organisation's system level that vertical segmentation is a characteristic of the entirety of sociality besides the horizontal structure.
\end{abstract}

Keywords: system theory, social theory, communication theory, autopoiesis, organisation, organisational and social communication

\section{The macro-societal context of the organisation's system level}

Niklas Luhmann is, beyond doubt, one of the theoreticians who have made the most profound impacts by analysing the complex systems of relationships of modernity. His system theory approach taking communication as a basic unit in the functioning of a society produced fundamental insights not only in the field of general social theory but also in relation to organisational communication. We are making an attempt to analyse the system level of the organisations that have been acquiring an increasingly high priority under the conditions and in the circumstances of modernity in the Luhmannian system theory, in the context of Luhmann's comprehensive social theory, because in our view the contents of organisational

Address for Correspondence: Bulcsu Bognár, email: bognar.bulcsu@btk.ppke.hu

Article received on the 16th Feb, 2013. Article accepted on the 12th Apr, 2013

Conflict of Interest: The author declares no conflict of interest.

Note: This publication was supported by the TÁMOP 4.2.1. B-11/2/KMR-2011-0002 grant of the European

Union and the Hungarian Government 
communication cannot be successfully outlined without the involvement of the entirety of social communication. This study gives an interpretation of his theory concerning organisational communication in the system of relationships of the system theory construction (Luhmann, 1987; conf. Karácsony 1990; 2000) that followed the autopoietic turn, focusing attention on the complex organisations emerging in modern society.

The issue of modern organisations is, in the context of this approach, therefore inseparable from the problem of the macro-level structure of modern society. The relationships between the functional subsystems of modernity is the cornerstone of the Luhmannian communication theory approach. For Luhmann's theory considered that functional subdivision of society to be the most important characteristic of modernity which, in contrast to the hierarchic organisation of the previous era, saw modern society definitely as a system comprising coordinated subsystems (Luhmann, 1987; 1998). The key proposition of this view of society is that none of the social subsystems are capable of influencing the functioning of the others because every subsystem decides autonomously on further connections of communication in line with its own self-reference distinction, as a consequence of which it is not even capable of contemplating the reference codes of other subsystems. Accordingly, modernity would differ from the earlier historical eras primarily in that the once (vertically) hierarchically organised communication of society would be replaced by a coordinating (horizontal) communication structure in which, for instance, the sphere of politics could not determine the economy's communication which is organised on the basis of economic viability and it would not be able to influence, for instance mass media's selection focusing on informativity. In this sense, therefore, it is not possible to talk about a preferred or focal subsystem that could influence the communication of the other subsystems.

On the other hand Luhmann's system theory was, for the most part, content with pointing out that the various subsystems had no means for interfering with the autonomous rationality of other subsystems, since impulses coming from one subsystem towards another can only be taken as mere irritation of the latter subsystem to which this subsystem responds on the basis of its own autopoiesis. The autopoiesis concept interpreted on the basis of the epistemological recognitions that originated obviously from the cell biological research dominating Luhmann's second creative period however, means not only separation but also the taking account of the environmental impacts. Nonetheless, Luhmann's interpretation seems as though it had focused only on one side of distinction, one of the characteristics of the communication scheme of impact (irritation) - response (adaptation) - reaction. It highlighted the relationship that expressed the subsystem's nature which uses its own internal elements as building blocks and that ensured its difference from the outside world and the self-referentiality of the subsystem. It paid less attention to how the environment that surrounds all subsystems and that is more complex than any subsystem can, if not determine, but influence, the contents of the system's autopoiesis.

Continuing Luhmann's train of thought however, may lead to revealing new dimensions of the particular organisation of modernity. Having accepted that there can be no central instance in modernity which could integrate the organisation of sociality, it inevitably follows from the connections of communication that the different functional subsystems need to have different weights. That is, the above special nature of social communication is bound to assume some kind of a hierarchic relationship even if it does not resolve the contents of the autopoiesis of the various subsystems. Applying the conclusions drawn from this train of thought to the conditions of European societal development that has created modernity, it is hardly possible to dispute for instance that the subsystem of the economy and that of politics can enforce its own rationality as irritation on the other subsystems to an extent that is different from the extent to which sports can assert its own. We are not only arguing here that the number of structural connections is larger in the case of the economy or politics than in 
the case of sports (as it is even possible to point out in a number of cases), but that the degree of irritation of certain subsystems on other subsystems can be a lot greater. Accordingly, certain subsystems in a more dominant position can therefore much more strongly dominate or determine the environment of another subsystem.

I attribute a structuring role to the different degrees of irritation as described above in that environmental impacts always affect the subsystems' autopoiesis. Although the subsystems make their selections in the process of communication on the basis of their own earlier (self-) referentiality but their own autopoiesis contents become fixed to at least the same extent as a result of and in response to environmental impacts and in the course of their own separation. If therefore a given subsystem receives impulses from the various subsystems in the form of irritations not at random frequency but some subsystems serve up challenges either much more often than do others or not necessarily more frequently but with a much more significant weight, and thus they somehow force the internal functioning of the subsystem to adapt to the impacts, then the development of its internal rationality is also more heavily affected by the subsystems in more dominant positions. What follows from it all is that it is possible to talk about a hierarchy or vertical connection between the functional subsystems, since some subsystems can - in the form of environmental impacts - more profoundly affect the forming of connections in social communication than other subsystems.

These conclusions however, do not override the Luhmannian recognition that the various subsystems have such autonomy which, in other aspects, expresses also the horizontal organisation of the various subsystems. On the other hand, there is good reason on the basis of the above to assume that subsystems are not only horizontally but also vertically organised. In my view this proposition is supported - in contrast to Luhmann's intents - by the interpretation he provides of modern society's self-description. In my view a number of its aspects also go to confirm that besides the definitely existing horizontal connections there are also vertical forms of organisation in the system of relationships among subsystems, because in discussing modernity's self-description Luhmann points out that there is a kind of a discrepancy between the structural connection of social communication and society's selfdescription (Luhmann, 1993a; 1993b). Although Luhmann often expresses that the existence of co-evolution is a pre-requisite for the connections between the different spheres of sociality, in this aspect he also perceives chronological differences as well. Accordingly, he clearly considers modern social communication to be possible to be characterised primarily by the horizontal relationships among functionally divided subsystems but he finds society's self-description to be dominated by the old European semantics which continues to express the semantics of the earlier era organised on the basis of stratification and which constitutes in this way a hierarchic perspective (Luhmann, 1991a; 1993c; 1996).

There is good reason to assume that this communication of homogeneous contents, which is coming from a variety of sources and which assumes a hierarchic relationship in the communication connections, imposes such an environmental impact on all spheres of sociality which cannot be ignored by the autopoiesis of the various systems either. In other words, if the communication impulses are not of a random nature in regard to the horizontal or vertical content of the structural connections but typically communicate that the communication organisations of sociality is determined by vertical organisation, then this factor plays role in the creation of vertical connections as well, besides the horizontal connections between the internal autopoieses of the various subsystems. ${ }^{\mathrm{i}}$ I am arguing that if the old European semantics of the description of the modern society emphasises the primacy of the economic and political subsystem that has been playing a central role in historical development, then this also affects the fact that communication expressing the rationality of these subsystems can more frequently and/or strongly appear as an irritation in the other

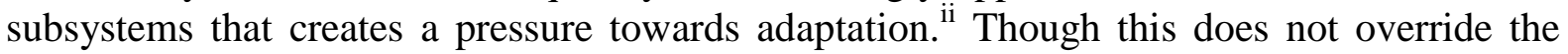


autopoiesis of the other subsystems, yet by imposing a pressure it is also responsible for hierarchic momentums to also appear between the subsystems in communication affecting the entirety of sociality.

\section{The functional subsystems and the character of organisational communication}

The following is an analysis of the consequences of the perspective change that can be worked out from the late Luhmannian theory in relation to the specific features of the organisational communication of modern society. I analyze the system level of the organisation of sociality focused on the special dynamic of the relationship between the organisation and the subsystems as well, as a sphere that also indicates the horizontal and vertical dimensions of structural connections in the modern society and that refers back to the dynamic between the subsystems. The discussion of this aspect can also be regarded as linked to Luhmann's late work. This is the period when his general system theory is increasingly highlighting the fluid nature of the connections besides the fixed nature of organisations and their features indicating stable structures. ${ }^{\text {ii }}$ Luhmann's change of perspective at the level of general system theory (Luhmann 1987; 1998) - for the very reason of his strive towards a high degree of internal coherence and of his capability of organising things in systems - did not leave his social theory unaffected either. Partly in relation to the autopoietic turn therefore, in his later works he revises the relationship between subsystems and organisations as well, and consequently he gets increasingly distanced from classical system theory which was perhaps most strongly linked to the name of Talcott Parsons (Parsons, 1962; 1967; 1969; $1971 ; 1977 ; 1991)$.

This turn in the Luhmannian social theory had an impact on the approach discussing the structural relationship between the subsystems and the organisations as well. Although Luhmann had not unambiguously linked organisations to the various subsystems even in the earlier period (to the extent his social theory permitted various organisations to come into existence independently from subsystems or in ways that could not definitely be tied to one or another subsystems), yet he regarded the majority of organisations primarily as social organisation forms assisting the functioning of the various subsystems (Luhmann, 1978; [1981] 2009a). At that time he still regarded the key task of organisations to be to enable the operation of the various subsystems by making decisions reflecting the rationality of the subsystems concerned. Accordingly, organisations were considered to be in place in order to tackle the difficulties of communication entailed by the increase in complexity and to provide for the subsystem's autonomy. At the same time, this organisational communication entailed the possibility of additional increase in complexity in the mutual relationship that characterised the mutually inter-dependent communication of the subsystem and the organisation and in which the organisation was just as capable of contributing to the separation of the subsystem's own rationality as it enabled further structural change. ${ }^{\mathrm{iv}}$

This interpretation obviously assumed a strong structural connection between the various subsystems and their respective organisation(s) in which institutional communication even got institutionalised in the subsystem's communication reflecting its rationality. In the relationship between a subsystem and its institution or system of institutions therefore, the possible forms of resolution of dual contingency were determined by stable structures. Accordingly, its contingency was designated by the structure of the institutionalised organisational decision making mechanism, referring, of course, back to the rationality of the subsystem as well. ${ }^{\vee}$ This framework of interpretation could, in its own particular way, clearly describe the process of institutionalisation that had a growing weight in modernity and it did 
not fail to describe the internal dynamic of the organisations and the subsystems either. ${ }^{\text {vi }}$ On the other hand, however, it could hardly give answers to the phenomena that could be observed at the system level of the organisations when social organisation had not necessarily been getting organised on the basis of organisational objectives.

The reason for the above is that organisational communication cannot only be organised on the basis of the organisation's explicit goal, in that decisions determining the system level can, in certain cases, be made on the basis of the rationality of other subsystems or of that of symbolically generalised communication media. We are talking here about the social phenomenon (still on the example of the economy) when the decision to be made by an industrial company or a bank is determined not by the drive towards economic viability but, say, by the rationality of the subsystem of politics or that of the communication medium of love. Based on the Luhmannian system theory there are at least two possibilities for interpreting this phenomenon that is so often experienced in our social world. Either we focus on the corruption of the organisational decision, saying that it applied not the rationality of the subsystem linked to the organisation but an external factor, a distinguishing structure that is alien to the subsystem's autopoiesis. Interpretation in this case leaves unaffected the concept of subsystems and organisations formulating a stable structure since in the interpretation of the social phenomenon we apply the assumption of another stable structure (that of politics or love) overriding the stable structure on hand (in this case the subsystem of the economy and the rationality of the organisation linked to it).

It is also possible, however, to give an interpretation to the phenomenon by reference to the fluidity of social communication. In this case we point out that the nature of social communication is determined by the temporary linkage of communication at any given point in time. Returning to the above example, if at the central bank the decision on hiring a new staff member is determined on the basis of political or personal (emotional) considerations then the organisational decision is interpreted on the basis of the preference code of the given communication situation. In other words, in the course of the sociological interpretation of the phenomenon organisational communication (similar to the system level of interaction) is assigned to one or another subsystem or communication medium depending on the area whose self-referentiality it applies in its communication. In pursuing this train of thought I cannot discuss here all of the social theory consequences of this change in perspective but it is clear from the late work of Luhmann (Luhmann, 1991b; 1998; 2005; 2006; 2009b) that mainly from the nineties on - while he did not neglect the role of stable structures either, he moved in essence in the direction of assuming fluid structures. In other words, in the last period of his work Luhmann concludes that modernity's complex system of relationships cannot be described without assuming prior structures fixed in the resolution of dual contingency - which are in this sense stable structures - and on the other hand he also notes that concrete social communication must always be interpreted on the basis of its momentary realisation and in this sense on the basis of its change.

The highlighting of the fluidity of social communication entails Luhmann's revaluation of what he explained about the relationship between subsystems and organisations earlier on. Although he continued to assert that the communication of subsystem can be linked to organisations (e.g. to the school, the hospital etc.) but it is always the concrete communication situation that determines the subsystem whose rationality dominates. (Luhmann's example for the fluidity of organisational communication in the case of the school is that its organisational communication is not necessarily linked to the subsystem of education, instead, the school's communication may be a covert form of religious or political communication as well (Luhmann, 1998a: 775). These later recognitions clearly relativise the earlier period's view concerning stable structure and the emphasis laid on the process of institutionalisation also changes. ${ }^{\text {vii }}$ 
The most important aspect of this analysis is however, that it yields new aspects for the interpretation of the relationship between the subsystems themselves as well. It seems to me that as a consequence of the application of the concept of fluidity, social theory explanation can also describe the structural connections between the subsystems rather in its dynamic. The description of society is therefore interpreted not so much on the basis of the stability between a subsystem and its organisations, rather, it provides more leeway for the dynamic of momentary communications which permits even connections to rather different subsystems in the case of the various organisations. This conceptual change definitely offers certain advantages from the aspect that it can more strongly demonstrate the increased mutual dependence of modern social communication and its more complex structural connections in comparison to the earlier historical era (Luhmann, 2009c). On the other hand, it definitely makes it more difficult to understand and interpret the autopoiesis of the various subsystems since if momentary communication shows frequently or continuously changing 'rationality preferences' then the time dimension of the self-referentiality of the various systems can also only be grasped by a more complex analysis. In other words, the exploring of the contents of communication referring back to earlier connections and pointing forward to future connections also takes a more complex analysis. ${ }^{\text {viii }}$

At the same time, problems arise in the case of the subsystems and their organisations, from the interpretation of corruption, or in other words, from the distinctions falling outside the rationality of the subsystem as well. If in the case of organisational communication we can rightly argue that its decision making mechanism can be linked in time to even multiple subsystem or to the symbolically generalised communication media, then it becomes more difficult to decide when we can talk about corruption and when we cannot. This is likely to be possible to decide on the basis of what the primary reference code in social communication is and in a simple case it may be decided on the basis of whether the structure of distinction is or is not aligned to the explicit goals of the institutionalised organisation. That is, returning to the earlier example, it can be determined on the basis of the realisation of corruption whether communication is determined by the distinction between economically viable from economically non-viable or some other reference code.

Even regardless of the problem of the fluidity of structures it is often difficult to find the borderline between the two. Returning to the example relating to the operation of the organisation it is difficult to decide whether the smile on the lady colleague's face is meant to enable smoother decision making in relation to the organisation's goals or whether it can be interpreted as the communication of intended seduction that can be linked to the symbolically generalised medium of love. Or whether a suggestion from the party headquarters concerning the choice of the new staff member should be interpreted as assistance given to facilitate the explicit goals of the organisation (the central bank) promoting economic viability as a preference code, or as interference on the part of politics overriding the rationality of the economic subsystem. Although subsequent connections of communication in time can provide an answer in the case of this problem to the occurrence or avoidance of corruption, ${ }^{\text {ix }}$ yet in the given communication situation this question cannot be decided. The reason for this is that communication can refer back to earlier structural connections, providing little help in the case of a momentary decision on whether communication is to be regarded as corruption or as communication of contents that fit in with the rationality of economic viability. ${ }^{\mathrm{x}}$

Returning to the issue of the fluidity of organisations it follows from Luhmann's organisation sociology in his late work that even in the case of organisations that are strictly subordinated to the various subsystems, specifically assisting the rationality of the subsystem concerned, it must be taken into account that the connections of communication are not exclusively linked to the organisation's explicit goal. Using the above example, the communication of a bank makes no sense if the subsystem's explicit rationality and decision making as determined by 
economic viability is demanded of it in every single instance of communication. At this point we are talking pointedly about that feature of communication in the case of which the various other subsystems or symbolically generalised communication mediums appear in institutional communication appear in institutionalised communication that this intervention can in no way be regarded - like in the above examples - as corruption or cases in which the suspicion of corruption arises. In the course of work the training of a new colleague (training subsystem), a discussion of the legality of the operation of the organisation (legal subsystem) or even friendship or affection between colleagues (symbolically generalised communication medium) can hardly or not necessarily be interpreted as corruption, even if it does not reflect the explicit goals of the organisation.

In regard to the connections between subsystems the fluidity of communication shows, at any rate, that even organisational communication definitely interpreted earlier on as the domain of a given subsystem is also intermingled with structural connections with subsystems that are also characterised by vertical organisations as well besides the horizontal ones. That is, the organisation's system level also reflects the historical contingency that offers greater opportunity for certain subsystems to appear in the communication of organisations that are determined predominantly by the rationality of another subsystem while other subsystems are provided with a much narrower manoeuvring room to structure the communication of 'alien' organisations. These appearances of different frequency and weight are shaping not only the specific features of the communication of the given organisation. Since organisational communication is an irritation even to a subsystem that is more dominantly linked to it, this presence constituting the logic of other subsystems results in an environmental impulse in organisational communication even at the system level of the organisation, which reflects the aspect of external rationality as well. In this way therefore, in addition to horizontal divisions vertical impacts can appear in a new relationship thereby also pointing out that the dynamic of subsystems can equally be characterised by both horizontal and vertical structures alike.

Finally, a brief reference needs to be made to the relationship emphasised in particular in Luhmann's late work, which refers to the profoundly different organisation of subsystems and organisations. While in his posthumous volume on organisational communication (Luhmann, 2001) characterised subsystems by horizontality and by lack of hierarchy, he considers it to be the main feature of organisations - besides focusing on decisions - that they retain their strongly hierarchic structure even in the circumstances of modernity. ${ }^{\text {xi }}$ While he describes the functional subsystems of modernity by inclusion which is considered to be the main characteristic, he regards the particular relationship; between inclusion and exclusion to be the central feature of organisations in which the threat of exclusion or its application is a key structure building element of the organisation. ${ }^{\text {xii }}$ In this late piece of work Luhmann emphasises the role of hierarchic conditions even more when he characterises three premises of the organisation's communication by decisions - communication through programmes, communication channels and persons - by strongly hierarchic features (Luhmann, 2001).

In accordance with the logic of the above discussion we can safely assume therefore that the hierarchic structure of modern organisations cannot leave the rationality of the subsystems unaffected either. As a matter of course, we are regarding the hierarchic organisation of organisational communication not as a feature fundamentally determining internal autopoiesis but as an environmental irritation, assuming the presence of a complex system of structural connections. Organisational communication is an environmental stimulus that cannot be disregarded by the self-referentiality of the subsystem, forcing the subsystems towards adaptation. Though this impact does not affect the distinguishing logic or the subsystems or the contents of their binary codes but - similarly to the characteristic old European semantics of the description of society - it strengthens the impacts of hierarchic 
construction structuring social communication. All these recognitions may offer new aspects for a more finely differentiated sociological description of modern society.

\section{NOTES}

${ }^{\mathrm{i}}$ It needs to be emphasised that my train of thought is not meant to argue - as does the critical discourse of the political left - that any and all social communication can only be interpreted in a hierarchic relationship and that it can envision only the validity of a conflict theory approach. [For a fully explicit explanation of this see the work of Bourdieu (Bourdieu, 1980; 1994), or Boltanski (Boltanski-Thévenot, 1999; Boltanski-Chiapello, 2001).] My argumentation is an attempt at correcting the consensus theory interpretation - in this aspect - of the Luhmannian approach. (Noting at this point again that the whole of Luhmann's social theory work cannot - in contrast to that of Parsons - be integrated in a framework of interpretation based on consensus theory or a conservative one. For more on the latter see: Bognár, 2009.)

${ }^{\text {ii }}$ Owing to constraints of volume it is not possible for me to discuss the debate between Luhmann and Willke in more detail. Therefore I only refer to the fact that Willke held that in modernity the state has powers overriding the coordinating structure among subsystems that restricts the autonomy of the subsystems (Willke, 1983). Although the approach attempting to carry on Luhmann's arguments along this line (Willke, 2001; 2003) emphasises the role of horizontal connections - similarly to my position - however, it perceives that not in the relationship among the various subsystems but identifies the hierarchic structure in the institutions determining the subsystems.

iii For more detail on this perspective, see: Bognár, 2009.

iv Luhmann set out his theory on organisational communication in three main publications (Luhmann, 1978; 2001; [1981] 2009a). Orientation is complicated however, by the fact that both his work reflecting the standpoint he took in the seventies and his piece of work elaborated in the nineties but published only after his death came out under the same title (Organisation und Entscheidung) although there are marked differences between the approaches taken in those two pieces of work. (For more on this see Ortmann, 2009)

$v$ For example, the rationality of the economy focusing on economic viability was determined at the level of organisational system in the institutions (industrial company, bank, etc.) that obtained their information input on the basis of the subsystem's preference code.

${ }^{v i}$ It is not surprising that Béla Pokol considered the very description of the process of institutionalisation to be one of the greatest merits of the Luhmannian social theory and he tried to continue elaborating that system theory focusing on the process of institutionalisation (Pokol, 1990).

vii It is also related to this conceptual change that Béla Pokol's interpretation assigning a greater role to institutionalisation fails to effectively find connections to Luhmann's late period though the integration of fluidity in the social theory does not necessarily undermine the assumption of stable structures and it does not rule out the integration of the society either. For more detail on this latter see Bognár, 2009.

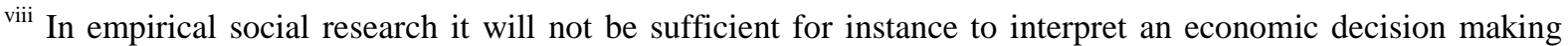
mechanism in a series of communications following one another, instead, there is a need for keeping tracks of the acts of communication that are broken off occasionally and then continued, that are determined by the preference code of economic viability, while the same principle is to be applied in observing the other preference codes that are likewise intermittently discontinued in both time and space.

${ }^{\text {ix }}$ Further connections of organisational communication can then more clearly show whether the smile on the face of the lady colleague or the activities of the colleague hired as recommended by the party headquarters are or are not in line with the explicit goals of the institutionalised organisation.

${ }^{x}$ This cannot be decided even if all of the earlier smiles of the lady colleague(s) were signs of intended seduction or the colleague recommended by the party headquarters always promoted political rationality instead of economic viability, because such prior structuring factors can only make the mode of resolving the dual contingency probable but not certain in the given communication situation. 


\footnotetext{
${ }^{\mathrm{xi}}$ Luhmann even goes as far as to explain that more complex organisations are inconceivable without hierarchy in the era of modernity. It is only by hierarchy that the various associations, federations, public administration organisations and undertakings can act as predictable collective actors since it is hierarchy that ensures that the instructions acceptable to the leaders of the organisation appear as the organisation's goals in the organisation's internal and external communication.

xii Since at the system level of the organisation the borderline can be drawn by distinguishing between membership and non-membership, exclusion can be achieved mostly by threatening expulsion from the organisation or by actually doing so, rather than by exclusion from organisational communication because this would mostly be concomitant to exclusion from the given subsystem as well which however, is not considered by Luhmann to be a characteristic of modern society, as he even explained in the above. (At least in the case of occidental development.)
}

\section{References:}

Bognár, B., 2009. Miképpen lehetséges szociális rend? A modernitás rendszerelméleti integrációja. Replika 66. $65-91$.

Boltanski, L. - Thévenot, L., 1999. The sociology of critical capacity. European Journal of Social Theory August 359-378.

Boltanski, L. - Chiapello, È., 2001. Die Rolle der Kritik in der Dynamik des Kapitalismus und der normative Wandel. Berliner Journal für Soziologie vol. 11., 4. 459-477.

Bourdieu, P., 1980. Le sens practique. Paris: Editions de Minuit.

Bourdieu, P., 1994. Raisons practiques. Sur la théorie de l'action . Paris: Seuil.

Karácsony, A., 1990: Niklas Luhmann társadalomelmélete és az autopoiézisz. Szociológia 1-2. 1-29.

Karácsony, A., 2000. Niklas Luhmann rendszerelmélete: a szociális világ mint kommunikatív teljesítmény. In:

Balogh, I. - Karácsony, A., Német társadalomelméletek. Témák és trendek 1950-töl napjainkig. Budapest: Balassi, 294-329.

Luhmann, N., 1978. Organisation und Entscheidung. Opladen: Westdeutscher Verlag.

Luhmann, N., [1984] 1987. Soziale Systeme. Grundriss einer allgemeinen Theorie. Frankfurt am Main: Suhrkamp.

Luhmann, N., 1991a. Am Ende der kritischen Soziologie. Zeitschrift für Soziologie April 147-152.

Luhmann, N., 1991b.: Soziologie des Risikos. Berlin: Walter de Gruyter.

Luhmann, N., [1980] 1993a. Gesellschaftsstruktur und Semantik. Studien zur Wissenssoziologie der modernen Gesellschaft. Band 1. Frankfurt am Main: Suhrkamp.

Luhmann, N., [1981] 1993b. Gesellschaftsstruktur und Semantik. Studien zur Wissenssoziologie der modernen Gesellschaft. Band 2. Frankfurt am Main: Suhrkamp. 
Luhmann, N., 1993c. „Was ist der Fall?” und „Was steckt dahinter?” Die zwei Soziologien und die Gesellschaftstheorie. Universitätsgespräche und Vorträge 3. Bielefeld: StadtBlatt Verlag. 1-24.

Luhmann, N., 1996. Tautologie und Paradoxie in den Selbstbeschreibungen der modernen Gesellschaft. In: Luhmann. Protest. Systemtheorie und soziale Bewegungen. Frankfurt am Main: Suhrkamp. 79-106.

Luhmann, N., [1997] 1998. Die Gesellschaft der Gesellschaft I-II. Frankfurt am Main: Suhrkamp.

Luhmann, N., 2001. Organisation und Entscheidung. Opladen, Wiesbaden: Westdeutscher Verlag.

Luhmann, N., 2005. Einführung in die Theorie der Gesellschaft. Dirk Baecker (szerk.). Heidelberg: Carl-Auer.

Luhmann, N., 2006. Beobachtungen der Moderne. Wiesbaden: VS Verlag.

Luhmann, N., [1981] 2009a. Organisationstheorie. In: uö: Soziologische Aufklärung 3. Soziales System, Gesellschaft, Organisation. Wiesbaden: VS Verlag, 387-478.

Luhmann, N., 2009b. Soziologische Aufklärung 5. Konstruktivistische Perspektiven. Wiesbaden: VS Verlag.

Luhmann, N., 2009c. Haltlose Komplexität. In: Luhmann: Soziologische Aufklärung 5. Konstruktivistische Perspektiven. 58-74.

Maturana, H. R. - Varela, F. J., 2010. Der Baum der Erkenntnis. Die biologischen Wurzeln menschlichen Erkennens. Frankfurt am Main: Goldmann.

Ortmann, G., 2009. Luhmanns entscheidungstheoretische Erwägungen. Soziale Systeme 15, Heft. 1. 36-45.

Parsons, T. - Shils, E. A., (ed.) 1962. Towards a general theory of action. New York: Harper and Row.

Parsons, T., 1967. Sociological theory and modern society. New York: Free Press.

Parsons, T., 1969. Politics and the social structure. New York: Free Press.

Parsons, T., 1971. The system of modern societies. Englewood Cliffs/New York: Prentince-Hall.

Parsons, T., 1977. Social systems and the evolution of action theory. New York: Free Press.

Parsons, T., [1951] 1991. The social system. London: Routledge.

Pokol, B., 1990.: Gesellschaftliche Teilsysteme oder professionelle Institutionsysteme? Reformulierungvorschläge zu Niklas Luhmanns Systemtypologie. Zeitschrift für Soziologie 5. 523-536.

Willke, H., 1983: Entzauberung des Staates. Überlegungen zu einer sozietalen Steuerungstheorie. Königstein/Ts: Athenäum.

Willke, H., 2001. Atopia. Studien zur atopischen Gesellschaft. Frankfurt am Main: Suhrkamp.

Willke, H., 2003. Heterotopia. Studien zur Krisis der Ordnung der moderner Gesellschaft. Frankfurt am Main: Suhrkamp. 